\title{
Effect of Long-Term Creep on Microstructure of a $9 \%$ Cr Heat Resistant Steel
}

\section{Valeriy Dudko $^{1 a}$, Alexandra Fedoseeva ${ }^{1 b}$, Pavel Kozlov ${ }^{2 c}$, Vladimir Skorobogatykh ${ }^{2 \mathrm{~d}}$, Izabella Shchenkova ${ }^{2 \mathrm{e}}$ and Rustam Kaibyshev ${ }^{1 f}$} ${ }^{1}$ Laboratory of Mechanical Properties of Nanostructured Materials and Superalloys, Belgorod State
University, Pobeda 85, Belgorod 308015, Russia

${ }^{2}$ Central Research Institute for Machine-Building Technology, Sharikopodshipnikovskaya 4, Moscow 115088, Russia

Email: avaleriy_dudko@yahoo.com, ${ }^{b}$ fedoseeva@bsu.edu.ru cpaul.kozlov@gmail.com, polyform_k@mail.ru, ein_material@mail.ru rustam_kaibyshev@bsu.edu.ru

Keywords: high-chromium heat resistant steel, martensite, tempering, carbides, mechanical properties.

\begin{abstract}
The effect of long-term creep at $600^{\circ} \mathrm{C}$ under $137 \mathrm{MPa}$ on the microstructure of a P92type steel was investigated. The microstructure after tempering consisted of laths with an average thickness of $400 \mathrm{~nm}$. Dispersion of secondary phases consists of $\mathrm{M}_{23} \mathrm{C}_{6}$ carbides with an average size of $85 \mathrm{~nm}$ located mainly on lath, block and prior austenite boundaries and MX carbonitrides with average size of $31 \mathrm{~nm}$ homogeniously distributed throughout. Creep with duration of 40738 hours led to coarsening of $\mathrm{M}_{23} \mathrm{C}_{6}$ carbides up to $182 \mathrm{~nm}$. Precipitation of Laves phase with an average size of $290 \mathrm{~nm}$ took place in both grip and gauge portions of ruptured specimen. Vanadium-rich MX particles were replaced by particles of Z-phase with sizes of 97 and $48 \mathrm{~nm}$ after long-term creep and aging, respectively. The average misorientation of the lath boundaries was approximately $2^{\circ}$ and scarcely varied during creep, while the mean lath thickness increased to 890 $\mathrm{nm}$ in gauge section of ruptured specimen and remained essentially unchanged in the grip section. Dislocation density decreased slightly under long-range aging and creep.
\end{abstract}

\section{Introduction}

High-chromium steels with tempered martensite lath structure (TMLS) are widely used as structural materials for steam boilers and pipelines operating at ultra-supercritical steam parameters [1]. The TMLS results from normalization being in fact air quenching and subsequent tempering. Alloying with $\mathrm{Cr}$ leads to precipitation of $\mathrm{M}_{23} \mathrm{C}_{6}$ particles on different boundaries which is essential for long term creep resistance at elevated temperatures [2,3]. Alloying with $\mathrm{Nb}$ and $\mathrm{V}$ provides dispersion strengthening. $(\mathrm{Nb}, \mathrm{V})(\mathrm{C}, \mathrm{N})$-type carbonitrides homogeneously precipitate throughout ferritic matrix. Substitutional solute atoms, such as Mo and $\mathrm{W}$, that have much larger radius than the solvent iron, are used as effective solid solution strengtheners [4]. However, coarsening of $\mathrm{M}_{23} \mathrm{C}_{6}$ particles, precipitation of Laves phase, transformation of $(\mathrm{Nb}, \mathrm{V})(\mathrm{C}, \mathrm{N})$-type carbonitrides into coarse Z-phase may occur during long-term creep that leads to breakdown of creep strength [1-4]. Coarsening of second phase particles is accompanied by corresponding lath growth [2,3]. These processes lead to degradation of TMLS and fast decrease in creep strength after long-term creep exposure. Efficiency of different second phase particles for microstructure stabilization was recently extensively examined for short-range creep [2-4]. In contrast, the influence of long-term creep on distribution of secondary particles and misorientations of lath boundaries, which are essentially dislocation low angle boundaries, has not been reported yet in sufficient detail.

The aim of the present study was to investigate the microstructure and a dispersion of secondary phases evolved in a P92-type steel after long-term creep at $600^{\circ} \mathrm{C}$ under $137 \mathrm{MPa}$. In particular, this study is focused on the changes of phase composition during long-term creep and misorientations of lath boundaries. 


\section{Experimental}

A P92-type steel (Fe-0.1C-0.17Si-0.54Mn-8.75Cr-0.21Ni-0.51Mo-1.60W-0.23V-0.07Nb, all in mass \%) was examined. The steel was subjected to solution treatment at $1050^{\circ} \mathrm{C}$ followed by air cooling. Next, the specimens were tempered for 3 hours at a temperature of $760^{\circ} \mathrm{C}$. A tensile specimen of $\varnothing 10 \mathrm{~mm}$ with a gauge length of $100 \mathrm{~mm}$ was subjected to creep test at a temperature of $600^{\circ} \mathrm{C}$ under an initial stress of $137 \mathrm{MPa}$ up to rupture, which occurred after 40738 hours. Microhardness measurements were carried out with a load of $0.5 \mathrm{~kg}$ on the central section along the specimen axis from thread to neck portions with a step of $\sim 2 \mathrm{Mm}$ in order to estimate the influence of long-range aging and creep deformation on softening. Techniques of structural characterization were reported previously [2-4]. The misorientations at the lath boundaries were studied using the conventional Kikuchi-line technique with transmission electron microscope (TEM) [5]. At least 40 boundaries were analysed for each specimen.
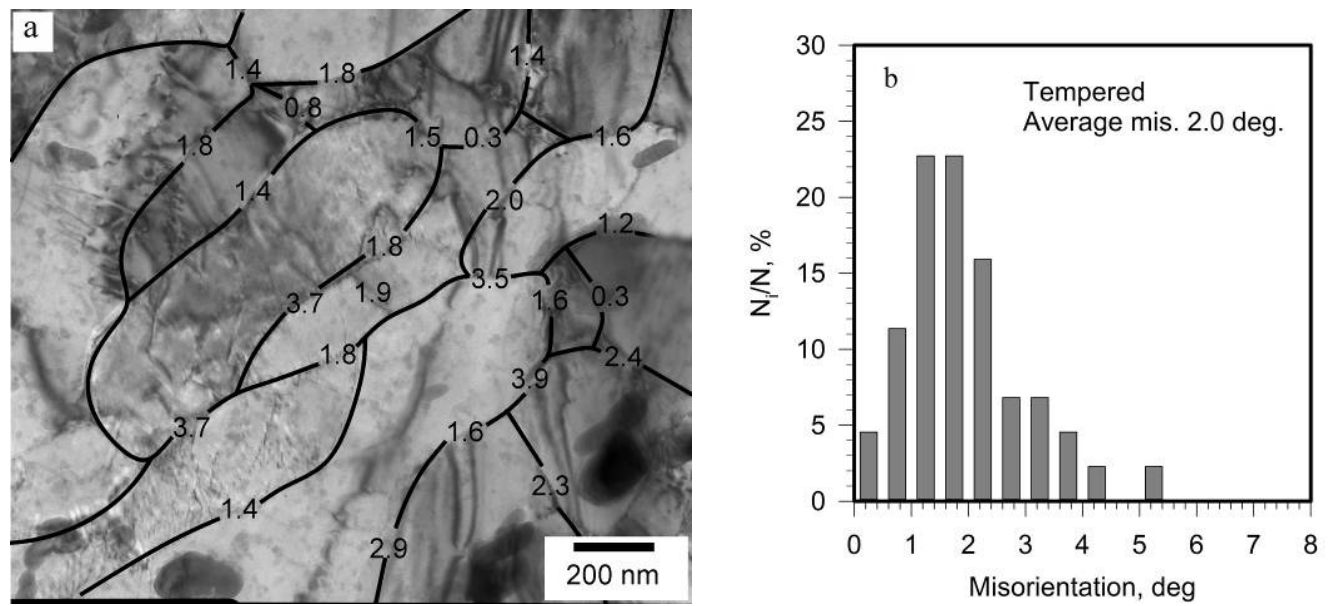

Figure 1. The lath structure of $\mathrm{P} 92$ steel after tempering at $760^{\circ} \mathrm{C}$ for 3 hours: (a) TEM picture with misorientations of lath boundaries; (b) the misorientation distribution of lath boundaries.

\section{Results and Discussion}

Microhardness measurement. The microhardness of tempered P92 steel was 217 HV. After creep test the hardness decreased, remarkably. However, the softening is not uniform along the crept specimen. The hardness gradually decreases from $195 \mathrm{HV}$ in the grip portion to $165 \mathrm{HV}$ in the portion close to the specimen neck. Therefore, long-range aging and creep provided -10 and $-24 \%$ softening, respectively, that is usually associated with microstructural changes $[2,3]$.

Tempered microstructure. Typical TMLS is shown in Fig. 1a. The mean lath thickness and the dislocation density within laths are $400 \mathrm{~nm}$ and $2.5 \times 10^{14} \mathrm{~m}^{-2}$, respectively. The majority of lath boundaries have misorientations below $3^{\circ}$ (Fig. 1b). The average misorientation of lath boundaries is $2.0^{\circ}$. The lath boundaries are decorated by particles of $\mathrm{M}_{23} \mathrm{C}_{6}$ with an average size of $85 \mathrm{~nm}$. Small MX carbonitrides precipitate homogeneously in the TMLS. The carbonitrides are wellseparated into $\mathrm{V}$-rich and $\mathrm{Nb}$-rich particles. The average sizes of $\mathrm{VX}$ and $\mathrm{NbX}$ carbonitrides are 35 and $26 \mathrm{~nm}$, respectively (Table 1).

Microstructural changes after creep and long-term aging. The results of the quantitative analysis of microstructures are summarized in Table 1. Long-term aging in the grip portion leads to an increase in the average transverse lath size from 400 to $570 \mathrm{~nm}$. The dislocation density negligibly decreases from $2.5 \times 10^{14}$ to $1.7 \times 10^{14} \mathrm{~m}^{-2}$. Creep deformation in the gauge portion results in more significant increase in the average lath thickness up to $890 \mathrm{~nm}$ (Fig. 2a) and slightly decreased dislocation density of $3.9 \times 10^{13} \mathrm{M}^{-2}$. Despite the considerable changes in the lath thickness and dislocation density, the average misorientation of the lath boundaries scarcely varies during the creep (Fig. 2b). The average misorientation of laths boundaries in crept specimen is $1.7^{\circ}$, which is slightly less than in the tempered steel. 
Table 1. Structural parameters after tempering, long-term creep and aging

\begin{tabular}{cccc}
\hline & Tempering & Creep & Aging \\
\hline Mean size of subgrain/lath, $\mu \mathrm{m}$ & $0.4 \pm 0.05$ & $0.89 \pm 0.10$ & $0.57 \pm 0.10$ \\
Dislocation density, $\mathrm{m}^{-2}$ & $2.5 \times 10^{14}$ & $4.68 \times 10^{13}$ & $1.74 \times 10^{14}$ \\
Mean size of $\mathrm{M}_{23} \mathrm{C}_{6}, \mathrm{~nm}$ & $85 \pm 20$ & $182 \pm 20$ & $152 \pm 20$ \\
Mean size of VX, nm & $35 \pm 5$ & $36 \pm 5$ & $38 \pm 5$ \\
Mean size of $\mathrm{NbX}, \mathrm{nm}$ & $26 \pm 5$ & $55 \pm 10$ & $55 \pm 10$ \\
Mean size of $\mathrm{Fe}_{2} \mathrm{~W}, \mathrm{~nm}$ & - & $293 \pm 20$ & $286 \pm 20$ \\
Mean size of $\mathrm{CrVN}, \mathrm{nm}$ & - & $97 \pm 20$ & $48 \pm 20$ \\
Hardness, $\mathrm{HV}$ & 217 & 165 & 195 \\
Plastic deformation, $\%$ & 0 & 54.6 & 0 \\
\hline
\end{tabular}

The quantitative analysis of second phase particles shows that the average size of $\mathrm{M}_{23} \mathrm{C}_{6}$ particles increases from $85 \mathrm{~nm}$ after tempering to $152 \mathrm{~nm}$ after long aging. The creep leads to remarkably larger $\mathrm{M}_{23} \mathrm{C}_{6}$ carbides in the gauge portion; their size equals $182 \mathrm{~nm}$. Figure 3 shows the size distribution of $\mathrm{M}_{23} \mathrm{C}_{6}$ carbides after tempering and creep test in the grip and gauge portions, respectively. The size distribution of $\mathrm{M}_{23} \mathrm{C}_{6}$ carbides for initial tempered state is characterized by a narrow peak at 50-100 $\mathrm{nm}$ (fig. 3a). This sharp peak decreases and shifts towards larger sizes in the grip portion of crept sample (fig. 3b) due to primary coarsening of $\mathrm{M}_{23} \mathrm{C}_{6}$ particles at the high-angle grain boundaries. The large $\mathrm{M}_{23} \mathrm{C}_{6}$ particles at high angle boundaries acquire an elongated shape, but small particles of $\mathrm{M}_{23} \mathrm{C}_{6}$ located at lath boundaries retain a round shape.

In the gauge portion of crept specimen no remarkable change in size distribution of $\mathrm{M}_{23} \mathrm{C}_{6}$ carbides was found in comparison with the grip section (fig. $3 \mathrm{c}$ ). The number of particles with sizes less than $100 \mathrm{~nm}$ decreases and large particles with sizes more than $500 \mathrm{~nm}$ appear on high-angle boundaries in the gauge portion of crept specimen (fig. 3c). Accelerate growth of large particles is caused by the coherency loss of $\mathrm{M}_{23} \mathrm{C}_{6}$ carbides [6] according to well-known Gibbs-Thomson scheme [7].

Typical $\mathrm{M}_{23} \mathrm{C}_{6}$ carbides and their chemical compositions after aging and creep are shown in Figures 4 and 5. Most of carbides retain round shape, while separate the coarse particles acquire plate-like shape. It is seen that the $\mathrm{Cr}$ concentration in $\mathrm{M}_{23} \mathrm{C}_{6}$ carbides increases after aging and creep. No particles of Laves phase were found after tempering because the tempering temperature exceeds the temperature of $\mathrm{Fe}_{2} \mathrm{~W}$ solvus [2,3]. The creep leads to precipitation of Laves phase in both grip and gauge portions of the sample (Figs. 4a,b). It is interesting to note that Laves phase particles have the same average size of $290 \mathrm{~nm}$ after long aging and creep (Table 2).

The average size of VX carbonitrides after long-term aging and creep test remains the same as after tempering. The average size of $\mathrm{NbX}$ carbonitrides increases to $55 \mathrm{~nm}$ in both gauge and grip portions of the crept specimen. The chemical composition of $\mathrm{VX}$ and $\mathrm{NbX}$ carbonitrides are stable against aging and creep (Fig. 5). Direct allotropic transformation of small V-rich carbonitrides into Z-phase CrVN was revealed after long-term creep test (Fig. 4). The particles of Z-phase replace relatively coarse particles of V-rich carbonitrides. Z-phase particles were observed in both gauge and grip sections of ruptured specimen. However, the average size of Z-phase particles in the grip portion is twofold less than that in the gauge part (Table 1). It should be noted that Nb-rich Z-phase was not found both after long-term aging and creep. The Z-phase particles are located mainly within laths and replace VX carbonitrides (Fig. 4). Z-phase and VX carbonitrides co-exist within laths (Fig. 4). Figures $5 \mathrm{~b}$ and $5 \mathrm{c}$ show the average chemical compositions of $Z$-phase particles after aging and creep, respectively. Creep leads to slightly higher Cr content in Z-phase particles.

The features of microstructural evolution during long-term creep test incorporate (i) coarsening of $\mathrm{M}_{23} \mathrm{C}_{6}$ carbides, (ii) the precipitation of Laves phase, (iii) replacement of V-rich $\mathrm{M}(\mathrm{C}, \mathrm{N})$ carbonitrides by Z-phase particles followed by their coarsening and (iv) transformation of lath boundaries to subgrain boundaries followed by their migration or lath coalescence. 

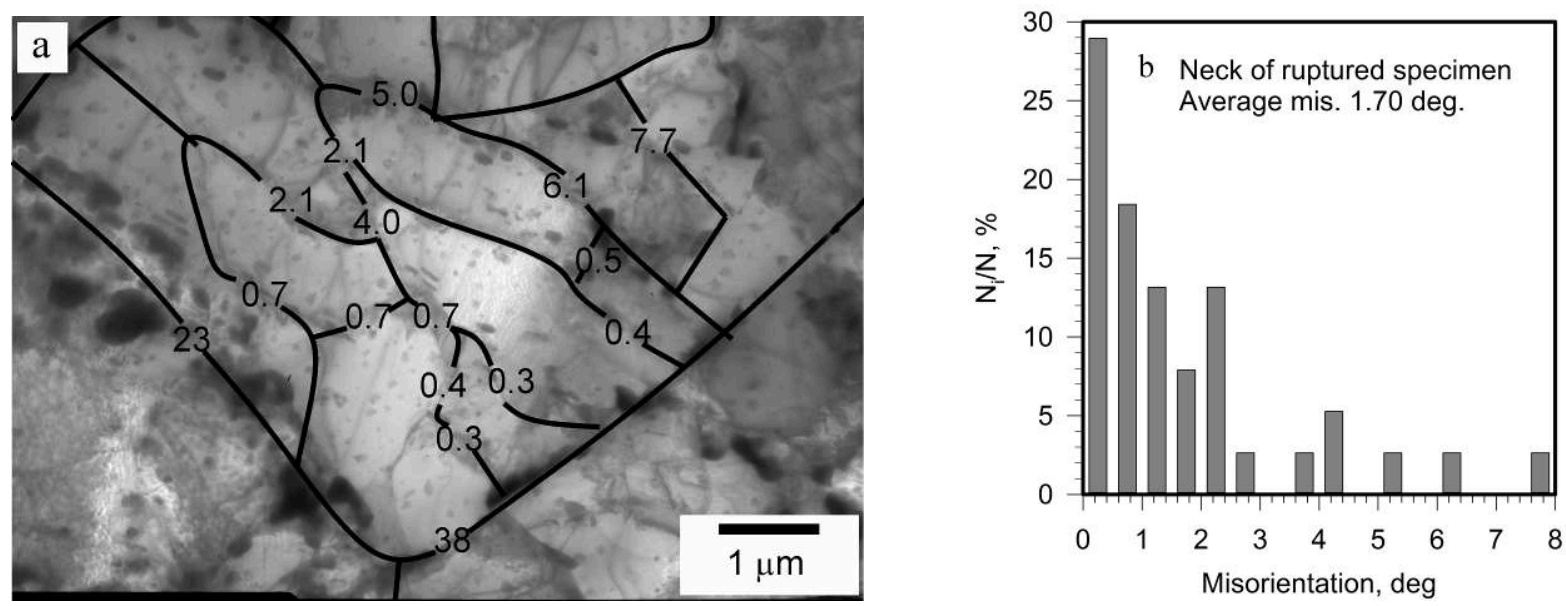

Figure 2. The lath structure of $\mathrm{P} 92$ steel after creep at $600^{\circ} \mathrm{C}$ under $137 \mathrm{MPa}$ during 40738 hours: (a) TEM micrograph with misorientations of lath boundaries, (b) lath misorientations distribution.

The average size of $\mathrm{M}_{23} \mathrm{C}_{6}$ carbides is close to Laves phase particles after creep test. It is apparent that the plastic deformation increases the coarsening rate of $\mathrm{M}_{23} \mathrm{C}_{6}$ carbides and Laves phase only during short-term creep [2,3]. Probably, plastic deformation facilitates the loss of coherency and disturbs orientation relationships between particles and ferritic matrix [6]. As a result, a rapid coarsening of $\mathrm{M}_{23} \mathrm{C}_{6}$ carbides and Laves phase occurs in the gauge part of specimen after short-term creep [2,3,6]. However, during long-term aging and creep the $\mathrm{M}_{23} \mathrm{C}_{6}$ carbides and Laves phase most likely lose their coherency with ferritic matrix previously and these grain boundary particles coarsen up to nearly the same sizes in the both portions of specimen.

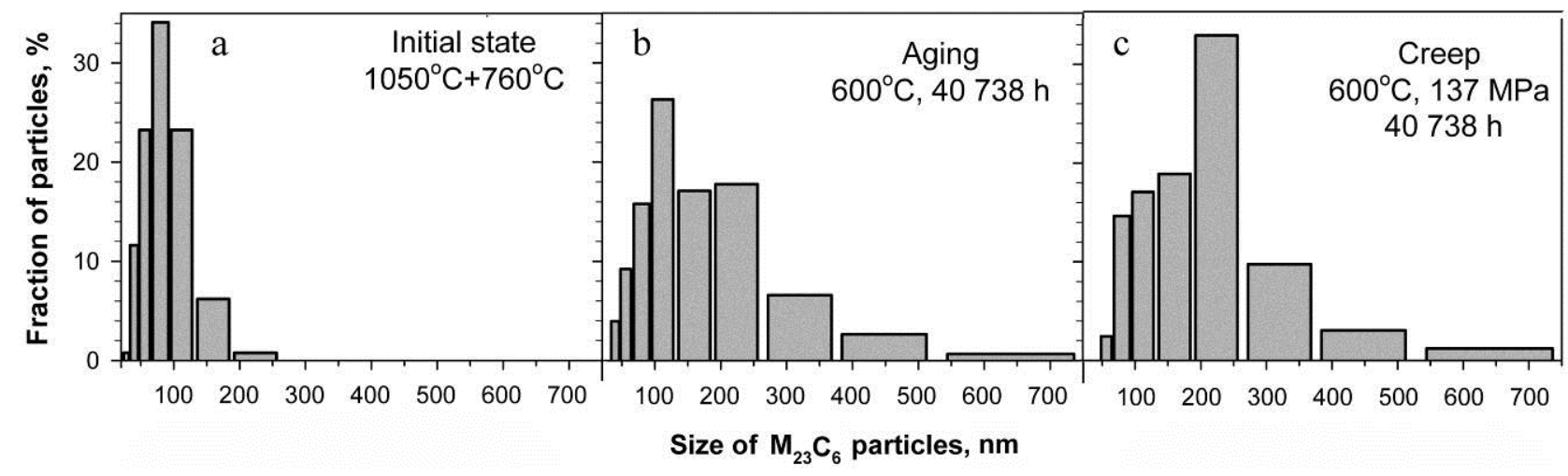

Figure 3. Size distributions of $\mathrm{M}_{23} \mathrm{C}_{6}$ carbides in $\mathrm{P} 92$ steel after tempering (a), aging (b) and creep (c).

The contribution of plastic deformation to coarsening of Laves phase is in acceleration of coherency loss of $\mathrm{Fe}_{2} \mathrm{~W}$ particles, precipitated on the boundaries of packets and laths of martensite $[4,8]$. This process occurs quickly and difference between average sizes of Laves phase in grip and gauge portions is significant when the rupture time is less than 2000 hours and volume fraction of Laves phase precipitated on high-angle boundaries is similar to that on low-angle boundaries [4]. If volume fraction of Laves phase allocated at high-angle boundaries is much bigger than that allocated at low-angle boundaries or time to rupture is more than 2000 hours the average sizes of Laves phase in gauge and grip portions of specimen are the same [8]. Thereby for long-term creep the average sizes of $\mathrm{M}_{23} \mathrm{C}_{6}$ carbides and Laves phase do not depend on plastic deformation. 

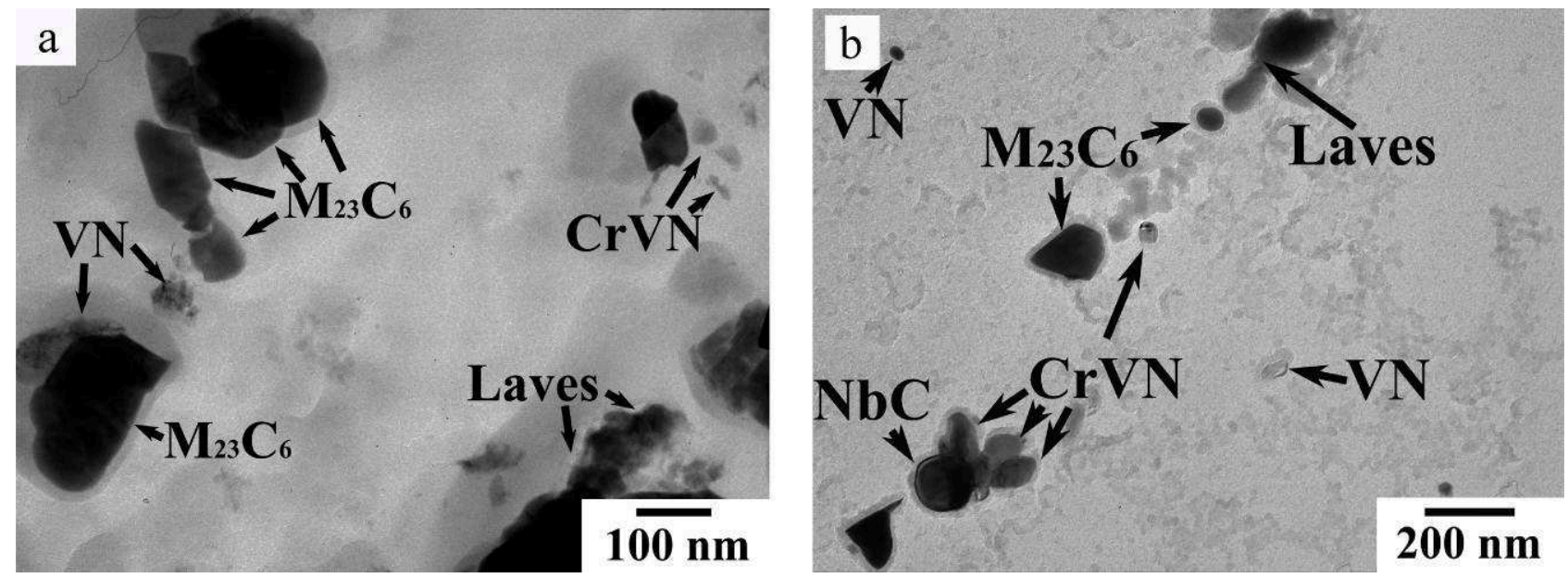

Figure 4. Extracted carbon replica with identified particles after long-term aging (a) and creep (b) of P92 steel.

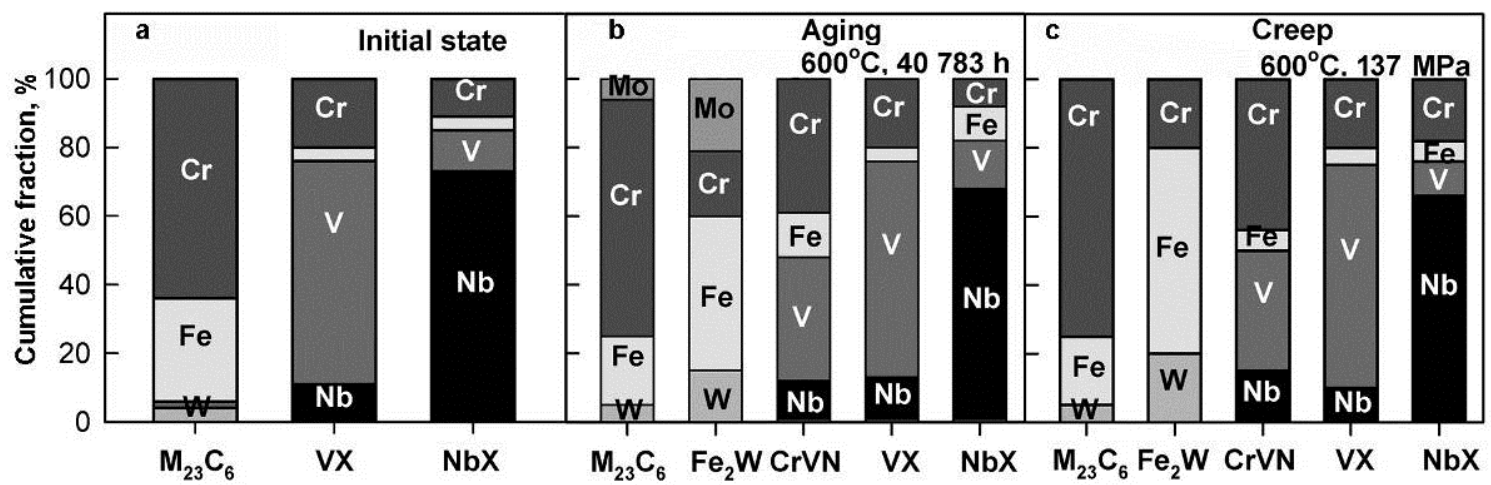

Figure 5. Average chemical composition of identified particles in P92 steel after tempering (a), aging (b) and creep (c).

It is worth noting that only V-rich Z-phase particles are precipitate during long-term aging and creep. In the present work, a lower fraction of $Z$ phase particles was observed in grip than in gauge portion of the ruptured sample. It is known [9] that cutting of coherent particles promotes the loss of coherency and facilitates their dissolution. This process occurs during creep in gauge part of specimen and accelerates both the appearance of Z-phase particles and their subsequent coarsening. The dissolution of small VX particles during creep promotes precipitation and coarsening of Zphase particles up to an average size of $97 \mathrm{~nm}$ after rupture (Table 2). This mechanism does not operate during the aging; and VX carbonitrides lose their coherency with matrix by operation of other mechanisms [7]. Only minor part of V-rich carbonitrides dissolves. The average size of Zphase particles in grip portion attains $48 \mathrm{~nm}$, only (Table 2). Thereby, the selection of the optimum size of V-rich carbonitrides, which will be resistant against cutting by dislocations, may increase the creep resistance of $9 \% \mathrm{Cr}$ martensitic steels.

Thermodynamically non-equilibrium dispersion of MX carbonitrides may remain untransformed into equilibrium Z-phase for a long period. In addition, the resulted size of Z-phase is higher than the size of preceding MX carbonitrides by a factor $\sim 2$, only. It seems if such the dispersion of carbonitrides, which is resistant against dissolution and coarsening, will remain in a $9 \% \mathrm{Cr}$ steel after long-range creep at high temperatures, so this material will be highly attractive for heatresistant applications. The selection of optimal chemical composition and tempering temperature, which have to provide this optimal dispersion of MX carbonitrides is the main aim for alloying philosophy of $9 \% \mathrm{Cr}$ steels, at present. Further development of microstructural design of these steels has to be directed to increasing resistance of VX carbonitrides against a cutting by dislocations and a loss of their coherency. 


\section{Summary}

The microstructure of P92-type steel after creep at $600^{\circ} \mathrm{C}$ under an applied stress of $137 \mathrm{MPa}$ for $40738 \mathrm{~h}$ was studied. The main results can be summarized as follows.

1. Long ageing and creep led to the same dispersion of $\mathrm{M}_{23} \mathrm{C}_{6}$ particles and Laves phase. The average size of $\mathrm{M}_{23} \mathrm{C}_{6}$ carbides increased from $85 \mathrm{~nm}$ in tempered condition to $152 \mathrm{~nm}$ after long ageing and $182 \mathrm{~nm}$ after creep. The average size of Laves phase was $290 \mathrm{~nm}$ after aging and creep.

2. A gradual transformation of V-rich carbonitrides into Z-phase occurred during long ageing and creep. The average size of Z-phase particles was $48 \mathrm{~nm}$ after long aging and $97 \mathrm{~nm}$ after creep.

3. The average misorientation of the lath boundaries was approximately $2.0^{\circ}$ and scarcely varied during creep, while the mean lath size increased from $400 \mathrm{~nm}$ in tempered condition to $890 \mathrm{~nm}$ after creep and $570 \mathrm{~nm}$ after aging and the dislocation density decreased from $2.5 \times 10^{14} \mathrm{~m}^{-2}$ after tempering to $4.68 \times 10^{13} \mathrm{~m}^{-2}$ after creep and $1.74 \times 10^{14} \mathrm{~m}^{-2}$ after aging.

\section{Acknowledgements}

This study was supported by Ministry of education and science under grant No. 14.A18.21.0760. Authors are grateful to staff of Joint Research Center, Belgorod State University, for their assistance with structural characterizations.

\section{References}

[1] F. Abe, Strengthening mechanisms in steel for creep and creep rupture, in: F. Abe, T.-U. Kern, R. Viswanathan (Eds.), Creep-resistant steels, Woodhead publishing ltd. Cambridge, 2008, pp. 279304.

[2] V. Dudko, A. Belyakov, D. Molodov, R.Kaibyshev, Microstructure Evolution and Pinning of Boundaries by Precipitates in a 9 pct Cr Heat Resistant Steel During Creep. Metall. Mat. Trans. A 44A (2013) 162-172.

[3] A. Kipelova, R. Kaibyshev, A. Belyakov, D. Molodov, Microstructure evolution in a 3\%Co modified P911 heat resistant steel under tempering and creep conditions, Mater. Sci. Eng. A 528 (2011) 1280-1286.

[4] A. Kipelova, A. Belyakov, R.Kaibyshev, Laves phase evolution in a modified P911 heat resistant steel during creep at 923 K, Mater. Sci. Eng. A 532 (2012) 71-77.

[5] S. Zaefferer, Computer-Aided Crystallographic Analysis in the TEM, Advances in Imaging and Electron Physics 125 (2002) 355-415.

[6] A. Kipelova, A. Belyakov, R. Kaibyshev, The crystallography of $\mathrm{M}_{23} \mathrm{C}_{6}$ carbides in a martensitic 9\% Cr steel after tempering, aging and creep, Phil. Mag. 93 (2013) 2259-2269.

[7] D.A. Porter, K.E. Esterling, M. Sherif, Phase transformations in metals and alloys (third edition), CRS Press, 2009.

[8] Q. Li, Precipitation of $\mathrm{Fe}_{2} \mathrm{~W}$ Laves Phase and Modeling of Its Direct Influence on the Strength of a 12Cr-2W Steel, Metall. Mater. Trans. 37A (2006) 89-97.

[9] M. Gazizov, R. Kaibyshev, Effect of over-aging on the microstructural evolution in an Al-Cu$\mathrm{Mg}$ alloy during ECAP at $300^{\circ} \mathrm{C}$, J. Alloy. Compd. 527 (2012) 163-175. 